\title{
Relationship between Gastric pH Measurement and Intra-abdominal Pressure in Patients Undergoing Laparoscopic Surgery
}

\author{
(D) Ayse Surhan Cinar, ${ }^{1}$ () Pinar Sayin, ${ }^{1}$ (1) Mustafa Fevzi Celayir ${ }^{2}$ \\ 'Department of Anesthesiology and Reanimation, University of Health Sciences Turkey, Sisli Hamidiye Etfal Teaching and Research \\ Hospital, Istanbul, Turkey \\ ${ }^{2}$ Department of General Surgery, University of Health Sciences Turkey, Sisli Hamidiye Etfal Teaching and Research Hospital, Istanbul, Turkey
}

\begin{abstract}
Objectives: Laparoscopic surgery (LS) is a safe and widely used technique. During LS, carbon dioxide insufflation may produce significant hemodynamic and ventilatory consequences, such as elevated intra-abdominal pressure (IAP) and hypercarbia. Splanchnic and cardiovascular blood flow can be affected by the elevated IAP, which can result in ischemia in the splanchnic region prior to hemodynamic changes. Changes in gastric $\mathrm{pH}$ may be an early precursor of changes in splanchnic blood circulation. This study investigated the relationship between gastric $\mathrm{pH}$ measurement and IAP in patients undergoing LS.

Methods: This study included 49 patients aged 18-65 years with American Society of Anesthesiologists (ASA) physical status I - III who were undergoing elective laparoscopic cholecystectomy. A gastric $\mathrm{pH}$ tonometer probe was applied using an orogastric catheter. Simultaneously, insufflation pressure, cardiac apex beat (CAB), and mean arterial blood pressure (MAP) values were recorded. Indirect IAP was then measured through the bladder. Measurements were performed at baseline; at 15, 30, and 60 minutes after onset of insufflation ( $\mathrm{Al} \mathrm{15,} \mathrm{Al} \mathrm{30}$, and $\mathrm{Al} \mathrm{60}$, respectively); and at the end of insufflation (EI). Two pH measurements were obtained with a gastric tonometer $\mathrm{pH}$ probe, using an automated function of the gastric tonometer to improve measurement reliability.

Results: IAP was significantly higher than baseline at $\mathrm{Al} 15, \mathrm{Al} 30, \mathrm{Al} 60$, and $\mathrm{El}(\mathrm{p}<0.001)$. The $\mathrm{pH}_{1}$ and $\mathrm{pH}_{2}$ levels were significantly lower at $\mathrm{Al} 15$ and $\mathrm{Al} 30$, compared with baseline $(\mathrm{p}<0.001)$. There were no significant differences between $\mathrm{pH}_{1}$ and $\mathrm{pH}_{2} \mathrm{measure}$ ments at $\mathrm{Al} 60$ and El. Compared with baseline, $C A B$ was significantly lower at $A I 15, A I 30, A l 60$, and $E l(p=0.001, p<0.001, p=0.006)$. There were no statistically significant differences in MAP changes at any time point.

Conclusion: Elevated IAP caused by $\mathrm{CO}_{2}$ insufflation during LS led to reductions of $\mathrm{pH}_{1}$ and $\mathrm{pH}_{2}$. There was a correlation between gastric $\mathrm{pH}$ measurement and IAP. Measurement of gastric $\mathrm{pH}$ may be useful to assess blood circulation in the splenic area during LS. Keywords: elevated intra-abdominal $\mathrm{pH}$; gastric $\mathrm{pH}$; laparoscopic surgery.

Please cite this article as "Surhan Cinar A, Sayin P, Celayir MF. Relationship between Gastric pH Measurement and Intra-abdominal Pressure in Patients Undergoing Laparoscopic Surgery. Med Bull Sisli Etfal Hosp 2020;54(4):463-468".
\end{abstract}

aparoscopic surgery (LS) has become a preferred mo-dality due to its advantages of minimal invasiveness, ability to mobilize the patient within a short time, and reduction of the period of hospitalization. ${ }^{[1]}$ During $\mathrm{LS}, \mathrm{CO}_{2}$ is used for intraperitoneal gas insufflation; high insufflation pressures are needed for good surgical view. However, elevated insufflation pressure and the presence of $\mathrm{CO}_{2}$ itself may present some problems. Respiratory and cardiovascu- 
lar changes caused by elevated IAP are well-known. ${ }^{[1]} \mathrm{Al}-$ though difficult, it is important to identify changes in microcirculation that are caused by elevated IAP, even when hemodynamic parameters are within normal ranges. ${ }^{[2]}$

Splanchnic and cardiovascular blood flow can be affected by elevated IAP. After insufflation, cardiac output and blood flow in the superior mesenteric artery and portal vein are progressively reduced; they return to pre-insufflation levels following deflation. Hepatic arterial blood flow does not change significantly, possibly due to compensatory mechanisms for the maintenance of hepatic blood flow. Mechanical compression of the splanchnic capillary beds due to elevated IAP may reflect elevated systemic vascular resistance. ${ }^{[2]}$

The splanchnic circulation receives $30 \%$ of cardiac output, resulting in regional storage. Circulation disorder primarily results in vasoconstriction in the splenic area. Thus, splenic circulation and mucosal $\mathrm{pH}$ may be impaired, although hemodynamic parameters are within the respective normal ranges. ${ }^{[1-3]}$ Gastric tonometry is a method for indirect measurement of splenic circulatory disorder, based on gastric $\mathrm{pH}^{[2,3]}$ The present study was performed to investigate the relationship between gastric $\mathrm{pH}$ measurement and IAP in patients undergoing LS in our hospital.

\section{Methods}

Approval for this prospective study was obtained from the Ethics Committee, formed in conjunction with the Anesthesia and Reanimation Clinic and General Surgery Clinic of Sisli Hamidiye Etfal Training and Research Hospital (approval no. 911-2015). All included patients provided written and verbal informed consent to participate.

\section{Inclusion and exclusion criteria}

This study included 50 patients aged $18-65$ years with American Society of Anesthesiologists (ASA) physical status I-III, who were undergoing elective laparoscopic cholecystectomy. Patients were excluded from the study if they met any of the following criteria: refusal to participate, pregnancy, advanced cardiac or respiratory disease, alkaline reflux gastritis or gastroesophageal reflux, alcohol or drug dependence, neuropsychiatric disease, metabolic disorders, electrolyte imbalance, severe dehydration or malnutrition, and emergency surgery. Demographic data, including age, sex, weight, height, and ASA physical status were recorded. None of the patients received premedication.

\section{Laparoscopy Technique}

All patients underwent intravenous cholangiography before the operation. Four ports were used for the procedure $(10,10,5,5 \mathrm{~mm})$. Patients were kept at $30^{\circ}$ head-down tilt during $\mathrm{CO} 2$ insufflation. After insertion of four cannulas, the position of the patient was changed to $15^{\circ}-20^{\circ}$ headup tilt. Standard techniques were used to perform laparoscopic cholecystectomy. Intra-abdominal pressure is adjusted between 12-14 $\mathrm{mm} \mathrm{Hg}$. Critical views of safety is of utmost importance to prevent bile duct injury. Clipping of the cystic duct and cystic artery is achieved from $10 \mathrm{~mm}$ epigastric port. Gallbladder extraction is generally done from either epigastric or umbilical port.

\section{Anesthesia Care}

After each patient had been taken to the operating room, D2 lead ECG, oxygen saturation $\left(\mathrm{SpO}_{2}\right)$, and noninvasive arterial blood pressure monitoring were implemented. Vascular hydration was initiated using a 20-gauge angiocath cannula. All patients underwent general anesthesia induction with $1 \mu \mathrm{g} / \mathrm{kg}$ fentanyl, $3 \mathrm{mg} / \mathrm{kg}$ propofol, and $0.6 \mathrm{mg} / \mathrm{kg}$ rocuronium. Intubation was performed with a cuff-straight classical intubation tube. Anesthesia was maintained with $1 \%-2 \%$ sevoflurane and a mixture of $50 \%$ oxygen $/ 50 \%$ air. An orogastric catheter was inserted after intubation; its location was confirmed by auscultation. A gastric tonometer $\mathrm{pH}$ measurement probe (Trip ${ }^{\mathrm{TM}}$; Tonometrics, Helsinki, Finland) was sent $50 \mathrm{~cm}$ through the orogastric catheter. Two $\mathrm{pH}$ measurements were performed simultaneously and recorded as initial $\mathrm{pH}$ values, using an automated function of the gastric tonometer to improve measurement reliability. Cardiac apex beat (CAB), mean arterial pressure (MAP), and $\mathrm{SpO}_{2}$ values were also recorded simultaneously. A urinary catheter was placed and the patient's urine was evacuated. A transducer for indirect IAP measurement (Holtech Medical, Charlottenlund, Denmark) was also inserted. The transducer was fixed in place at the symphysis pubis. After injection of $70 \mathrm{ml}$ of saline into the bladder, the urinary catheter was clipped and IAP measurement was recorded. The operation was then initiated. Gastric $\mathrm{pH}, \mathrm{CAB}, \mathrm{MAP}$, and $\mathrm{SpO}_{2}$ measurements were recorded during the period of intraperitoneal gas insufflation. Insufflation pressures (IP) and IAP measurements made indirectly through the bladder were recorded. All measurements were repeated at 15 , 30, and 60 minutes after onset of insufflation (Al 15, Al 30, and $\mathrm{Al} 60$, respectively) and at the end of insufflation (EI) (before extubation); all values were recorded.

Anesthesia was stopped when the operation was completed. Patients whose spontaneous respiration and airway reflexes returned to normal were extubated after neuromuscular blockade antagonization with $0.01 \mathrm{mg} / \mathrm{kg}$ atropine and $0.03 \mathrm{mg} / \mathrm{kg}$ neostigmine. Patients with Aldrete Recovery Score $\geq 9$ were considered to be stable and were transferred to the postoperative care unit after waking. The duration of anesthesia (time from induction to patient recovery), operation time (time from skin incision to last 
suture), and time of insufflation (time from the beginning to the end of $\mathrm{CO}_{2}$ insufflation) were recorded. All complications related to anesthesia or surgery were recorded.

\section{Statistical Analysis}

SPSS 15.0 for Windows (SPSS Inc., Chicago, IL, USA) was used for statistical analysis. Descriptive statistics are shown as the mean, standard deviation, and minimum, maximum for numerical variables. Differences in numerical variables in the dependent group were examined using the Friedman test because a normal distribution was not present. Relationships between numerical variables were examined by Spearman correlation analysis, because no parametric test was suitable for analysis. In all analyses, $p<0.05$ was considered to indicate statistical significance.

\section{Results}

Overall, 75 patients were assessed for eligibility and 50 patients met the inclusion criteria. During the study period, one patient was excluded from the analysis due to $\mathrm{pH}$ metre failure. Finally, 49 patients were included in the analysis. Figure 1 shows a flow diagram of the study. The mean patient age was $45.3 \pm 12.4$ years. Twenty-six of the 49 patients were men; the remaining 23 patients were women. Mean anesthesia time, mean surgical time, and mean insufflation time were $70.5 \pm 15.4,55.8 \pm 16.8$, and $44.8 \pm 15.7$ minutes, respectively. None of the patients had complications related to surgery or anesthesia.

The mean IP, IAP, $\mathrm{pH}_{1^{\prime}}, \mathrm{pH}_{2^{\prime}} \mathrm{CAB}$, and MAP measurements are presented in Table 1. Variations of IP, IAP, $\mathrm{pH}_{1}, \mathrm{pH}_{2}, \mathrm{CAB}$, and MAP are presented in Table 2. The IAP, $\mathrm{pH}_{1}$, and $\mathrm{pH}_{2}$ levels decreased as IP increased. The relationships among IP, IAP,

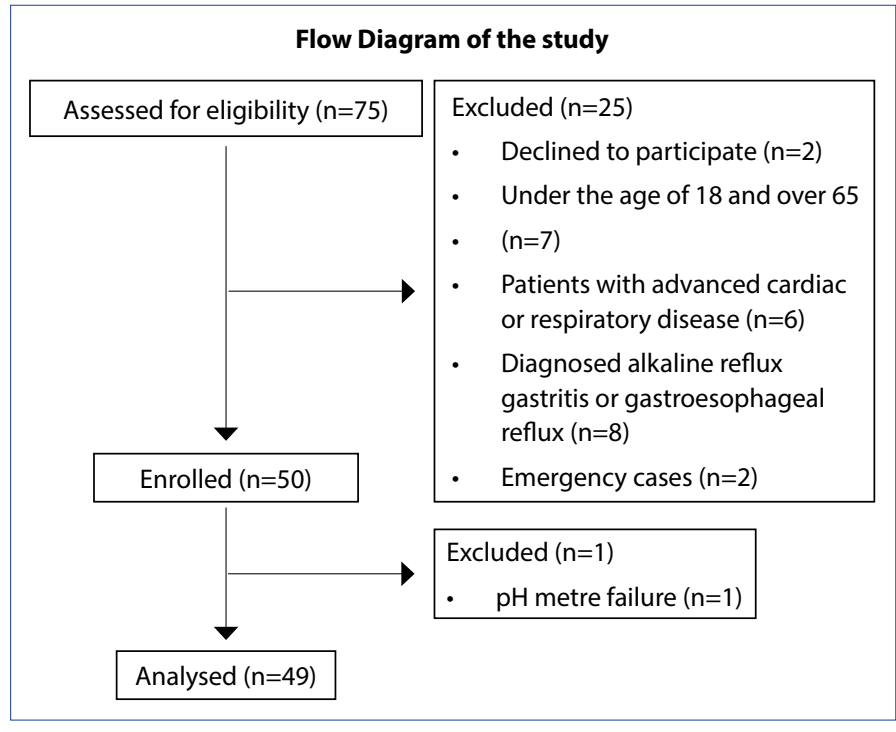

Figure 1. Flow diagram of the study.

$\mathrm{pH}_{1}$, and $\mathrm{pH}_{2}$ are presented in figure 2. Elevation of IAP, due to $\mathrm{CO}_{2}$ insufflation during $\mathrm{LS}$, led to reductions of $\mathrm{pH}_{1}$ and $\mathrm{pH}_{2}$. There was an inverse correlation between gastric $\mathrm{pH}$ measurement and IAP elevation. IAP was significantly higher than baseline at $\mathrm{Al} 15, \mathrm{Al} 30, \mathrm{Al} 60$, and $\mathrm{El}$ (all $\mathrm{p}<0.001$ ). The $\mathrm{pH}_{1}$ and $\mathrm{pH}_{2}$ levels were significantly lower at $\mathrm{Al} 15$ and Al 30, compared with baseline (all $p<0.001$ ). The $\mathrm{pH}_{2}$ levels were also significantly lower at El, compared with Al 60 $(\mathrm{p}=0.005)$. Changes in $\mathrm{pH} 1$ and $\mathrm{pH} 2$ at other time points were not statistically significant (all $p>0.05$ ). $C A B$ levels were significantly lower than baseline at $\mathrm{Al} 15, \mathrm{Al} 30$, and $\mathrm{EI}$ $(p=0.001, p<0.001$, and $p=0.006$, respectively). There were no statistically significant differences regarding changes in $C A B$ and MAP at any other time points (all $p>0.05$ ).

Table 1. Mean Insufflation pressure $(\mathrm{mmHg})$, mean intraabdominal pressure $(\mathrm{mmHg})$, mean $\mathrm{pH}_{1}$, mean $\mathrm{pH}_{2}$ mean measurements of the study group

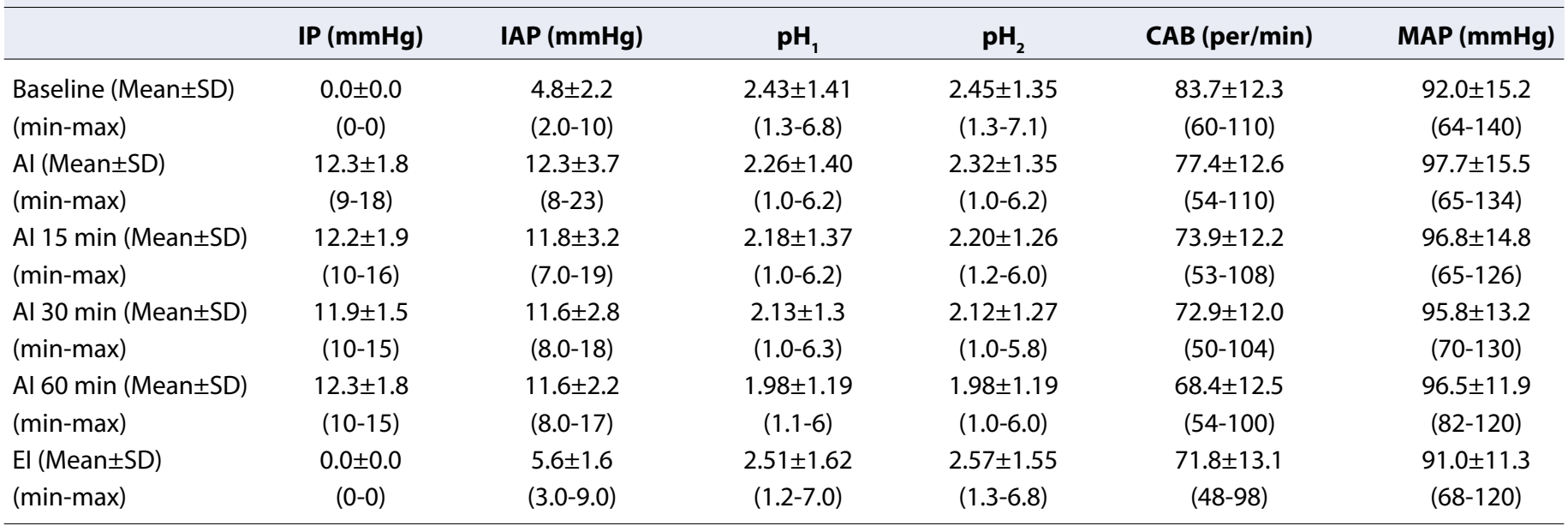

Al: After Insufflation; B: Baseline; Al 15 min: $15^{\text {th }}$ minutes of insufflation; Al 30 min: $30^{\text {th }}$ minutes of insufflation; Al 60 min: $60^{\text {th }}$ minutes of insufflation; El: End insufflation; CAB: Cardiac Apex Beat; MAP: Mean Arterial Pressure; IP: Insufflation pressure; IAP: Intraabdominal pressure. 
Table 2. Variations of $\mathrm{pH}_{1}, \mathrm{pH}_{2}$, Cardiac Apex Beat and Mean Arterial Pressure over time

\begin{tabular}{|c|c|c|c|c|}
\hline & $\begin{array}{c}\mathbf{p H}_{1} \\
\mathbf{p}\end{array}$ & $\begin{array}{c}\mathbf{p H}_{2} \\
\mathbf{p}\end{array}$ & $\begin{array}{c}\text { CAB } \\
\mathbf{p}\end{array}$ & $\begin{array}{c}\text { MAP } \\
\mathbf{p}\end{array}$ \\
\hline Al vs. B & $<0.001$ & 0.001 & 0.001 & 0.046 \\
\hline Al 15 min vs $B$ & $<0.001$ & $<0.001$ & $<0.001$ & 0.079 \\
\hline Al 30 min vs $B$ & $<0.001$ & $<0.001$ & $<0.001$ & 0.118 \\
\hline $\mathrm{Al} 60$ min vs $\mathrm{B}$ & 0.020 & 0.008 & 0.006 & 0.119 \\
\hline El vs. B & 0.906 & 0.417 & $<0.001$ & 0.801 \\
\hline Al 15 min vs El & 0.110 & 0.011 & 0.042 & 0.746 \\
\hline Al 30 min vs. Al 15 min & 0.719 & 0.297 & 0.228 & 0.446 \\
\hline Al 60 min vs. Al 30 min & 0.675 & 0.755 & 0.482 & 0.501 \\
\hline El vs. Al $60 \mathrm{~min}$ & 0.075 & 0.005 & 0.698 & 0.047 \\
\hline
\end{tabular}

Al: After Insufflation; B: Baseline; Al 15 min: $15^{\text {th }}$ minutes of insufflation; Al 30 min: $30^{\text {th }}$ minutes of insufflation; Al $60 \mathrm{~min}: 60^{\text {th }}$ minutes of insufflation; El: End insufflation; CAB: Cardiac Apex Beat; MAP: Mean Arterial Pressure.

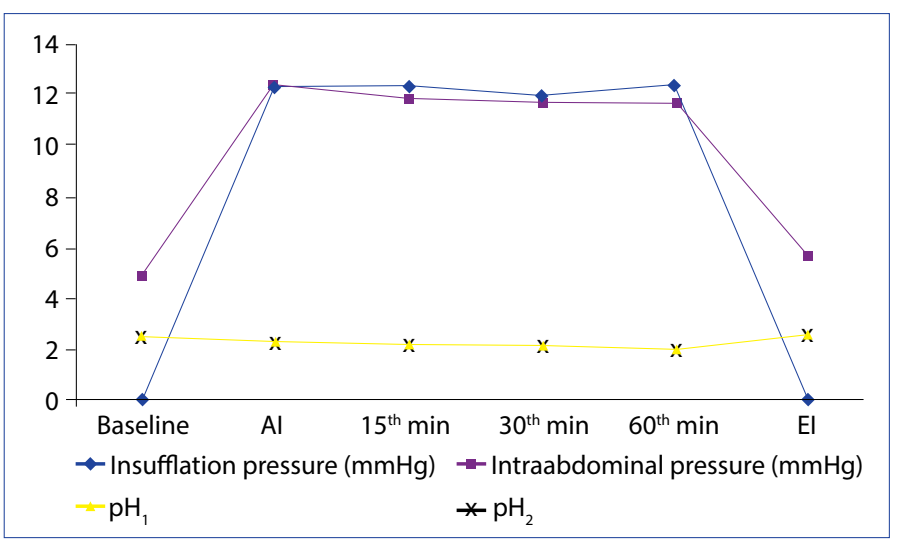

Figure 2. The relationships among IP, IAP, $\mathrm{pH}_{1}$, and $\mathrm{pH}_{2}$.

\section{Discussion}

We conducted a prospective study in a cohort of 49 patients undergoing laparoscopic cholecystectomy surgery. During the insufflation phase, gastric $\mathrm{pH}$ measurements were obtained. Our results demonstrated that elevation of IAP, due to $\mathrm{CO}_{2}$ insufflation during $\mathrm{LS}$, led to reductions of $\mathrm{pH}_{1}$ and $\mathrm{pH}_{2}$. There was an inverse correlation between gastric $\mathrm{pH}$ measurement and IAP elevation.

The term splanchnic circulation refers to all blood flow originating from the celiac, superior mesenteric, and inferior mesenteric arteries, which is widely distributed to all abdominal viscera and important organs (e.g., spleen, liver, intestine, omentum, and pancreas). Thus, the splanchnic circulation can act as a site of cardiac output regulation, as well as a blood reservoir. Therefore, evaluation of splanchnic circulation is very important. Notably, small bowel perforations due to ischemia after laparoscopic cholecystectomy have been reported in the literature. Therefore, studies in this field are always important. ${ }^{[4]}$
Mucosal pH measurement is an indicator of direct splanchnic blood flow and oxygen consumption. Reductions of $\mathrm{pH}$ measured using a gastric tonometer are correlated with reductions of blood flow and oxygen consumption; they may constitute a sensitive and specific indicator of mucosal ischemia. ${ }^{[5-7]}$

In a meta-analysis involving measurement of gastric mucosal pH in critically ill patients, Zhang et al. ${ }^{[8]}$ showed that gastric $\mathrm{pH}$ had important prognostic value in early diagnosis and in reducing mortality. In a review regarding gastric tonometry, Taylor et al. ${ }^{[9]}$ emphasized that measurement of gastric $\mathrm{pH}$ is helpful in early diagnosis of tissue oxygenation and end-organ damage in patients in the intensive care unit. They suggested that splanchnic ischemia may be the first indicator of shock. Recent findings indicated that intramucosal $\mathrm{pH}$ measurement is a simple, noninvasive monitoring technique, which is useful for guiding treatment and improving survival in critically ill patients. ${ }^{[9]}$

These data suggest that information regarding splanchnic circulation can be obtained using the same technique in LS procedures, where assessment of organ perfusion is important. Although blood pressure, heart rate, and urine output may be normal in LS, splanchnic blood circulation may be affected by various factors (e.g., anesthesia, hypoxia, and hypercapnia). The relationships between intestinal lesions and clinical parameters in IAP, as well as their safety thresholds, remain unknown. ${ }^{[10]}$

One of these factors comprises the elevation of IAP caused by $\mathrm{CO}_{2}$ insufflation during $\mathrm{LS}$. Elevated $\mathrm{CO}_{2}$ insufflation pressure results in reduction of splanchnic blood flow. Especially at insufflation pressures $>20 \mathrm{mmHg}$, venous return is disrupted, cardiac output decreases, and vascular resistance increases. ${ }^{[1,11,12]}$ Vasoconstriction occurs in the splanchnic area prior to hemodynamic changes; splanchnic ischemia may be the first precursor of reductions in microcirculation. Knolmayer et al. performed gastric $\mathrm{pH}$ measurement in an intraperitoneal pig model between $8-18 \mathrm{mmHg}$; they compared the results with cardiac output, wedge pressure measurement, mixed venous blood gas, and lactate levels from the pulmonary artery catheter. ${ }^{[13]}$ The results showed that gastric $\mathrm{pH}$ change is an early indicator of ischemia. In a comparison of laparoscopic cholecystectomy with open surgical technique, Eleftheriadis et al. ${ }^{[14]}$ used transcutaneous laser-Doppler flowmetry to evaluate liver microcirculation; they also performed simultaneous gastric $\mathrm{pH}$ measurement. Notably, Eleftheriadis et al. found deterioration of liver microcirculation in $\mathrm{LS}$ and reductions of concurrent gastric $\mathrm{pH}$ measurements. In the present study, CAB measurements showed reductions at all time points after onset of insufflation compared to baseline; no differences were 
found in mean arterial pressures. Reductions of $C A B$ may be correlated with anesthesia; this change is statistically, but not clinically, significant. Therefore, we cannot state that hemodynamic changes were not present in pneumoperitoneum. However, gastric $\mathrm{pH}$ values decreased with the onset of insufflation, compared to baseline measurements; this suggested that gastric $\mathrm{pH}$ measurement may provide early signs of splanchnic ischemia. Correa-Martin et al. increased IAP at 20 and $30 \mathrm{mmHg}$ by $\mathrm{CO}_{2}$ insufflation in pigs for 5 hours; ${ }^{[15]}$ they observed a reduction of gastric $\mathrm{pH}$ at $30 \mathrm{mmHg}$ at 90 minutes, whereas they observed an elevation of lactate level only at 180 minutes. Therefore, they considered gastric $\mathrm{pH}$ measurement to be a more sensitive means of evaluating splanchnic hypoperfusion. Caldwell et al. showed that intramucosal pH decreased to 7.14 at IAP $>20 \mathrm{mmHg}$; moreover, intramucosal pH decreased to 6.98 at IAP $>40 \mathrm{mmHg} .^{[11]}$ However, the values in those studies were much higher than the pressures currently used in LS.

Çelik et al. examined the effects of five insufflation pressures $(8,10,12,14$, and $16 \mathrm{mmHg})$ on gastric $\mathrm{pH}$ in a study of patients undergoing laparoscopic cholecystectomy; they found no differences between groups. ${ }^{[16]}$ Moreover, they found that insufflation pressures of $8-16 \mathrm{mmHg}$ used during LS were safe values at which splanchnic circulation was not impaired. Thaler et al. ${ }^{[17]}$ reported no changes in intramucosal pH when IAP was maintained below $15 \mathrm{mmHg}$. Our findings differed from those of Çelik et al. and Thaler et al., because we found a reduction of gastric $\mathrm{pH}$ after insufflation, even at pressures as low as $12 \mathrm{mmHg} \cdot{ }^{[16,17]}$ The differences among studies may be related to the techniques used; notably, Çelik et al. ${ }^{[16]}$ and Thaler et al. ${ }^{[17]}$ used gastric tonometers, whereas we used $\mathrm{pH}$ meters for measurement. The gastric tonometer measures the $\mathrm{CO}_{2}$ levels and calculates the $\mathrm{pH}$ with the Henderson-Hasselbalch equation; therefore, it is an indirect means of measuring intragastric

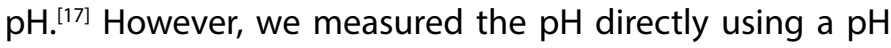
meter, which is more sensitive than a tonometer for detection of $\mathrm{pH}$ changes.

In the present study, the lowest and highest insufflation pressures were $8 \mathrm{mmHg}$ and $18 \mathrm{mmHg}$; the average pressure was $12 \mathrm{mmHg}$. IAPs measured after insufflation ranged from 7 to $23 \mathrm{mmHg}$, with a mean of $11.6 \mathrm{mmHg}$. Although LS was performed at low pressures, significant $\mathrm{pH}$ changes were detected at all time points after onset of insufflation, compared to baseline. There was a correlation between IAP elevation and $\mathrm{pH}$ change.

Luo et al. ${ }^{[18]}$ evaluated the effects of prolonged pneumoperitoneum on oxidative stress and bowel ischemia in robotic-assisted laparoscopic radical prostatectomy for up to 4 hours; they found an elevation of malondialdehyde level and a reduction of gastric $\mathrm{pH}$ level from the onset of insufflation. In that study, an insufflation pressure of $15 \mathrm{mmHg}$ was used; ischemic changes continued until 2 hours after the end of insufflation. In the present study, we used an average of 44 minutes of insufflation and found no correlation between the duration of insufflation and $\mathrm{pH}$ change. We found that the $\mathrm{pH}$ values returned to their initial values at 15 minutes after the end of insufflation.

Some studies have examined the effects of open surgery and LS on splanchnic circulation based on oxidative stress response and gastric $\mathrm{pH}$ changes; they found no significant differences between the two techniques. ${ }^{[17,19,20]}$ Our study had some limitations in that there was no comparison group, the number of patients was low, short-term LS was performed, and gastric tonometry was not used for measurement.

\section{Conclusion}

Elevation of IAP, due to $\mathrm{CO}_{2}$ insufflation during $L S$, led to reductions of $\mathrm{pH}_{1}$ and $\mathrm{pH}_{2}$. There was a correlation between gastric $\mathrm{pH}$ measurement and IAP elevation. Gastric $\mathrm{pH}$ measurement may be useful during LS to evaluate blood circulation in the splanchnic area.

\section{Disclosures}

Ethics Committee Approval: Ethics Committee Approval: The study was approved by the Local Ethics Committee of Sisli Hamidiye Etfal Training and Research Hospital (approval number: 911-2015, year 2015).

Peer-review: Externally peer-reviewed.

Conflict of Interest: None declared.

Authorship Contributions: Concept - S.C., P.S., M.F.C.; Design S.C., P.S., M.F.C.; Supervision - S.C., P.S., M.F.C.; Materials - S.C., P.S., M.F.C.; Data collection \&/or processing - S.C., P.S., M.F.C.; Analysis and/or interpretation - S.C., P.S., M.F.C.; Literature search - S.C., P.S., M.F.C.; Writing - S.C., P.S., M.F.C.; Critical review - S.C., P.S., M.F.C.

\section{References}

1. Hirvonen EA, Poikolainen EO, Pääkkönen ME, Nuutinen LS. The adverse hemodynamic effects of anesthesia, head-up tilt, and carbon dioxide pneumoperitoneum during laparoscopic cholecystectomy. Surg Endosc 2000;14:272-7. [CrossRef]

2. Hatipoglu S, Akbulut S, Hatipoglu F, Abdullayev R. Effect of laparoscopic abdominal surgery on splanchnic circulation: historical developments. World J Gastroenterol 2014;20:18165-76. [CrossRef]

3. Ishizaki Y, Bandai Y, Shimomura K, Abe H, Ohtomo Y, Idezuki Y. Changes in splanchnic blood flow and cardiovascular effects following peritoneal insufflation of carbon dioxide. Surg Endosc 1993;7:420-3. [CrossRef]

4. Leduc LJ, Mitchell A. Intestinal ischemia after laparoscopic chole- 
cystectomy. JSLS 2006;10:236-8.

5. Knichwitz G, Mertes N, Kuhmann M. Improved PCO2 measurement in six standard blood gas analysers using a phosphate-buffered solution for gastric tonometry. Anaesthesia 1995;50:532-4.

6. Clark $\mathrm{CH}$, Gutierrez $\mathrm{G}$. Gastric intramucosal pH: a noninvasive method for the indirect measurement of tissue oxygenation. Am J Crit Care 1992;1:53-60. [CrossRef]

7. Myers SI, Hernandez R, Miller TA. Differing effects of anesthetics on splanchnic arterial blood flow during hemorrhagic shock. J Appl Physiol (1985) 1994;76:2304-9. [CrossRef]

8. Zhang X, Xuan W, Yin P, Wang L, Wu X, Wu Q. Gastric tonometry guided therapy in critical care patients: a systematic review and meta-analysis. Crit Care 2015;19:22. [CrossRef]

9. Taylor DE, Gutierrez G. Tonometry. A review of clinical studies. Crit Care Clin 1996;12:1007-18. [CrossRef]

10. Caldwell CB, Ricotta JJ. Changes in visceral blood flow with elevated intraabdominal pressure. J Surg Res 1987;43:14-20.

11. Párraga Ros E, Correa-Martín L, Sánchez-Margallo FM, CandanosaAranda IE, Malbrain MLNG, Wise R, et al. Intestinal histopathological changes in a porcine model of pneumoperitoneum-induced intra-abdominal hypertension. Surg Endosc 2018;32:3989-4002.

12. Joris JL, Noirot DP, Legrand MJ, Jacquet NJ, Lamy ML. Hemodynamic changes during laparoscopic cholecystectomy. Anesth Analg 1993;76:1067-71. [CrossRef]

13. Knolmayer TJ, Bowyer MW, Egan JC, Asbun HJ. The effects of pneumoperitoneum on gastric blood flow and traditional hemodynamic measurements. Surg Endosc 1998;12:115-8. [CrossRef]
14. Eleftheriadis E, Kotzampassi K, Botsios D, Tzartinoglou E, Farmakis $\mathrm{H}$, Dadoukis J. Splanchnic ischemia during laparoscopic cholecystectomy. Surg Endosc 1996;10:324-6. [CrossRef]

15. Correa-Martín L, Castellanos G, García-Lindo M, Díaz-Güemes I, Sánchez-Margallo FM. Tonometry as a predictor of inadequate splanchnic perfusion in an intra-abdominal hypertension animal model. J Surg Res 2013;184:1028-34. [CrossRef]

16. Celik V, Salihoglu Z, Demiroluk S, Unal E, Yavuz N, Karaca S, et al. Effect of intra-abdominal pressure level on gastric intramucosal pH during pneumoperitoneum. Surg Laparosc Endosc Percutan Tech 2004;14:247-9. [CrossRef]

17. Thaler W, Frey L, Marzoli GP, Messmer K. Assessment of splanchnic tissue oxygenation by gastric tonometry in patients undergoing laparoscopic and open cholecystectomy. Br J Surg 1996;83:6204. [CrossRef]

18. Luo CF, Tsai YF, Chang CH, Wu CT, Yu HP. Increased oxidative stress and gut ischemia caused by prolonged pneumoperitoneum in patients undergoing robot-assisted laparoscopic radical prostatectomy. Acta Anaesthesiol Taiwan 2011;49:46-9. [CrossRef]

19. Ozmen MM, Kessaf Aslar A, Besler HT, Cinel I. Does splanchnic ischemia occur during laparoscopic cholecystectomy? Surg Endosc 2002;16:468-71. [CrossRef]

20. Berger M, Goedeke J, Hubertus J, Muensterer O, Ring-Mrozik E, von Schweinitz $D$, et al. Physiological impact of pneumoperitoneum on gastric mucosal $\mathrm{CO} 2$ pressure during laparoscopic versus open appendectomy in children. J Laparoendosc Adv Surg Tech A 2012;22:107-12. [CrossRef] 